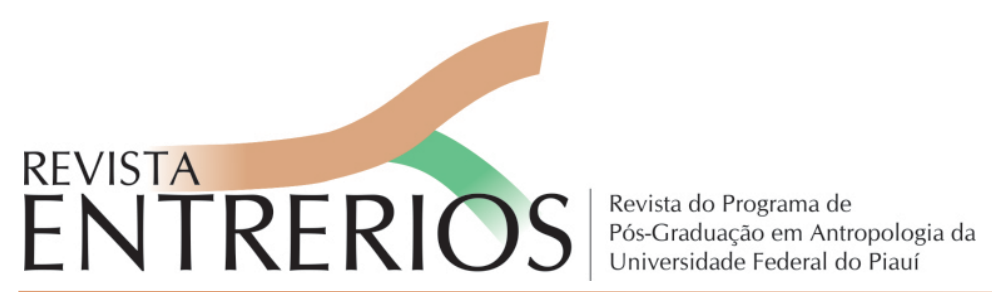

\title{
Antropologia, Psicanálise e reflexões sobre o campo antropológico na contemporaneidade: Entrevista com Luiz Fernando Dias Duarte
}

\author{
Lilian Leite Chaves \\ PNPD/PPGAS/UFRN \\ lilianlchaves@gmail.com \\ Maria Lídia Medeiros de Noronha Pessoa \\ PPGAnt/UFPI \\ lidianoronha@uol.com.br \\ Mônica da Silva Araujo \\ PPGAnt/UFPI \\ monicasaraujo@yahoo.com.br \\ Potyguara Alencar dos Santos \\ PNPD/PPGAnt/UFPI \\ potyguara.alencar@gmail.com
}

Na seção periódica de entrevistas, o segundo número da Revista EntreRios tem o prazer de publicar o diálogo realizado com a o professor Dr. Luiz Fernando Dias Duarte, antropólogo vinculado ao Programa de Pós-Graduação em Antropologia Social da Universidade Federal do Rio de Janeiro (PPGAS/Museu Nacional); com formação em Direito (UERJ/1972), mestrado em Antropologia Social (UFRJ/1978), doutorado em Ciências Humanas (UFRJ/1985) e pósdoutorado pelo Groupe de Sociologie Politique et Morale, da École des Hautes Etudes en Sciences Sociales (EHESS/1991).

Nos três blocos de perguntas que aqui divulgamos, tem-se uma parte sintética de alguns dos principais contributos reflexivos de um intelectual que, desde a década de 1970, vem a organizar um programa transdisciplinar de projetos e formação de pesquisadores, que envolvem inquietações em conexões entre a Antropologia, a Psicanálise e a Psicologia Social. Desse pensador, apontamos sua capacidade de produzir uma inversão analítica produtiva, essa que, hoje, é copiada por boa parte da Antropologia Social feita no Brasil: em vez de partir das circunscrições disciplinares que inspiram a exploração interpretativa de categorias recorrentes 
na construção da modernidade ocidental pretensamente "universal", a exemplo das noções de pessoa, doença e família, o que sua proposta produziu foi uma visada sobre os antigos e atuais fenômenos contemporâneos brasileiros que dessas categorias se salientam, para só depois desenhar as inspirações temático-teóricas particulares que suas realidades propõem. Tal disposição lhe rendeu uma coleção de trabalhos com uma assinatura intelectual preponderante lembramos, nesse momento, Da Vida Nervosa (nas classes trabalhadoras urbanas), de 1986, também da coletânea Doença, sofrimento e Perturbação: perspectivas etnográficas, de 1998, e, mais recentemente, O corpo moral: fisicalidade, sexualidade e gênero no Brasil (2018) -, afora uma série de outros novos projetos e formação de pesquisadores que continuam a multiplicar a herança dos procedimentos heurísticos inaugurados pelo professor Luiz Fernando Dias Duarte ao longo da sua trajetória.

\section{Trajetória intelectual e espaço de produção}

EntreRios: A sua tese enfocando a construção de identidades sociais nas classes trabalhadoras inaugura o importante eixo de reflexão sobre "o nervoso e as perturbações físico-morais". A que você credita o vigor desse trabalho, uma vez que ele se tornou uma referência importante sobretudo para pesquisas no campo da antropologia da saúde?

Luiz Fernando Dias Duarte: A maior novidade do livro Da Vida Nervosa era, àquela época (a tese é de 1985 e o livro de 1986), a apresentação de uma análise etnográfica profunda das classes populares brasileiras em um eixo "estrutural-culturalista", distinto do "materialculturalismo" da escola de Bourdieu, por exemplo (apesar de uma forte e bem vinda influência deste outro lado), ou das muitas interpretações inspiradas no marxismo. Também foi uma novidade a apresentação de um modelo comparativo sobre as noções de pessoa holista (popular) e de pessoa individualista (classes médias letradas); o que tinha muitas implicações em termos da relação com os saberes psi. Os esquemas analíticos de Louis Dumont sobre o Ocidente se construíram sobre temáticas muito abrangentes e macroestruturais, enquanto que minha contribuição era a de trazê-los para uma análise etnográfica localizada. É claro que também tinha um grande sabor de novidade - no Brasil - o tratamento analítico sério da configuração cultural dos "nervos", muito estudada pela Antropologia Médica nos EUA, sobretudo a respeito das populações "latinas".

EntreRios: É possível perceber, considerando parte pela sua produção bibliográfica, pelos trabalhos que orientou e pelas disciplinas que ministrou no PPGAS-MN desde a década de 1980, um interesse pelas discussões acerca da doença mental, da saúde mental e ou tros termos que na contemporaneidade podem ser inseridos nessas rubricas. Como você situa esse interesse e como você avalia o envolvimento da Antropologia com essas temáticas?

Luiz Fernando Dias Duarte: A pesquisa sobre os "nervos" levou-me a uma sistemática tentativa de compreender a história das representações e práticas relativas às "perturbações físico-morais" (locução proposta por mim, que procurava evitar os aspectos etnocêntricos, anacrônicos e controversos de "doença mental", "loucura", "saúde mental" etc.) e de dialogar com os saberes psi (psiquiátricos, psicológicos e psicanalíticos) para avançar na compreensão comparada mais ampla sobre as diferentes concepções da pessoa humana. A antropologia (e a sociologia) já dispunha de algumas linhas de trabalho interessantes, mas um tanto diferentes do caminho que pretendia trilhar. Tratava-se sobretudo da "etnopsiquiatria" e da "etnopsicanálise", por um lado, e da Escola de Cultura e Personalidade e do "interacionismo simbólico", por outro. Aquela era uma época em que um espírito “antipsiquiátrico" grassava em todo o Ocidente (sob diferentes títulos) - e uma certa aliança se esboçava por baixo dessas difere- 
-ntes linhas. Foucault, Goffman, Reich, Marcuse, Laing \& Cooper, Guattari, Basaglia eram nomes inspiradores, articulados numa trama de revisão dos pressupostos biomédicos da compreensão e terapêutica das "perturbações". A psicanálise se encontrava em um momento de auge em sua influência midiática e formava um pano de fundo inevitável para o pensamento antropológico (como reconhecia Lévi-Strauss de um modo geral; mas sobretudo em A Eficácia Simbólica e O Feiticeiro e sua Magia).

\section{Antropologia, psicanálise e outras disciplinas.} acadêmica?

EntreRios: Como se manifestou a aproximação junto à Psicanálise durante a sua trajetória

Luiz Fernando Dias Duarte: Fui (e sou) profundamente influenciado pela Psicanálise, tanto como intelectual como pessoa, já que passei anos reclinado no divã. Tive e tenho um enorme respeito e curiosidade sobre tudo o que decorreu da inestimável construção analítica de Freud. Mas, ao mesmo tempo, uma consciência muito vívida dos seus limites, ao tentar lidar com os fenômenos coletivos, literalmente sociais. Nunca acompanhei linearmente a etnopsiquiatria, por exemplo - muito desacreditada, à época, pelo estruturalismo. Mas sou fascinado pelos bons (e raros) exemplos de uma aproximação complexa entre os enfoques psicanalítico, histórico, sociológico e antropológico - como é o caso do magnífico livro de Jacques Maître sobre Santa Teresinha de Jesus.

EntreRios: Qual a importância dos psicanalistas Sigmund Freude Jacques Lacan às interpretações dos seus temas de pesquisa?

Luiz Fernando Dias Duarte: Sofri muita influência do método interpretativo de Freud em seus delineamentos gerais, ao praticar antropologia - e já escrevi sobre esse paralelismo epistemológico e metodológico entre as duas disciplinas (seguindo a sugestão de Foucault a esse respeito em As Palavras e as Coisas). Tive menos influência de Lacan, que sempre achei excessivamente hermético, embora seu tema do "mito individual do neurótico" me tenha sido útil.

EntreRios: Em quais temas de suas pesquisas e estudos você destaca essa interseção com a Psicanálise?

Luiz Fernando Dias Duarte: Certamente a intersecção já existia na pesquisa de doutorado sobre os "nervos". O modelo do "nervoso" que propus se opõe diretamente à concepção psicologizada da pessoa moderna, cuja versão mais profunda, coerente e significativa considero ser a da psicanálise. Isso me levava a "telescopizar" a psicanálise como fenômeno social, como uma Weltanschauung (nos termos inquietos de Freud) específica, dentro da história da cultura ocidental moderna. Escrevi um artigo (com Emerson Giumbelli) sobre o profundo enraizamento da psicanálise na história da cultura cristã - por exemplo. Todos os desenvolvimentos posteriores de meu trabalho conservam os traços desse viés analítico - com maior clareza em todo o período do projeto sobre a constituição do campo psi no Brasil; que conduzi juntamente com Jane Russo e a psicóloga Ana Jacó-Vilela. Agora, quando me dedico mais ao papel das noções de "natureza" e "vida" na cosmologia ocidental, a psicanálise volta a estar na mira; mas, mais uma vez, como objeto de localização histórica e ideológica, e não como fonte de lições epistemológicas e metodológicas.

EntreRios: Existe, na Antropologia contemporânea, especialmente a que se faz no Brasil, preocupações em se considerar a psicanálise como um mecanismo interpretativo da vida social? 
Luiz Fernando Dias Duarte: Acho que não existe mais nenhum sinal dessa disposição no campo nacional, assim como decresceu fortemente em todo o cenário antropológico internacional. O último antropólogo a usar sistematicamente de recursos da psicanálise em suas análises no Brasil foi Roger Bastide. Houve, porém, posteriormente, muitos psicanalistas alguns bem instruídos em ciências sociais - que propuseram análises da cultura ou da sociedade nacional à luz da psicanálise (Contardo Calligaris, Jurandir Freire Costa, Octavio de Souza, Sérvulo Figueira, Ana Maria Nicolaci-da-Costa, Ana Carolina Lobianco etc.). O último etnopsicanalista a trabalhar com as sociedades indígenas do Brasil - que eu saiba - foi o Waud Kracke, que faleceu recentemente. A polêmica entre G. Obeyesekere e Marshall Sahlins terminou com vantagem para este último - do ponto de vista da recepção pelo campo. O que persiste são heranças daquele movimento mais voltadas para a organização de terapêuticas que acolhem os modelos e agentes tradicionais; como vamos ver, mais adiante, a propósito de Tobie Nathan, por exemplo.

EntreRios: A Antropologia considera o conceito de inconsciente na interpretação dos fatos sociais? Por exemplo, a respeito dos sonhos nas experiências dos sujeitos em diversos contextos sociais, sejam de modernidade ou de tradicionalidade?

Luiz Fernando Dias Duarte: A antropologia operou longamente com um conceito parecido com o de inconsciente da psicanálise. Mas, na verdade, diferente: o de Freud é uma instância estruturada do psiquismo, com suas regras organizacionais e princípios dinâmicos específicos. O da antropologia é talvez melhor descrito como um mero "não-consciente", aquelas dimensões da experiência fenomenal que não se manifestam explicitamente no pensamento das gentes - e cujo estatuto é sempre muito controverso. A etnopsiquiatria e a etnopsicanálise fizeram uso do primeiro conceito em situações socioculturais múltiplas. Os antropólogos em geral puderam lançar mão de materiais liminares, como os sonhos, em muitas situações etnográficas, mas apenas como mais uma manifestação do simbolismo enfrentado nos mitos e nos rituais - até porque a fronteira entre sonho e vigília, tal como conceituada no Ocidente, nem sempre tem o mesmo sentido alhures. No bojo de uma valorização relativamente recente da experiência pessoal do antropólogo em seu campo, na produção mesma de sua interpretação de outrem, busca-se incluir nos registros de campo materiais associados ao "inconsciente" psicanalítico, como sonhos, fantasias, lapsos, associações livres, fluxos de consciência etc.

EntreRios: A "etnopsicanálise", termo empregado primeiramente por Georges Devereux na década de 60, em que discutia a importância de se pensar a interseção entre Antropologia e Psicanálise, tanto na interpretação psíquica quanto nos fenômenos sociais. Atualmente, Tobie Nathan, criou o termo "etnopsiquiatria" e vem realizando pesquisas e práticas terapêuticas no Centro Georges Devereux em Paris VII. Experiência semelhante vem sendo desenvolvida no Centro di Ricerca e formazione Clínica Gabriel Ubaldine Slonina na Itália pelo antropólogo e psicoterapeuta Gabriel Maria Sala que criou o termo "Teatro etnoclínico". Enfim, são experiências que aliam a psicanálise, a psiquiatria à Antropologia como um campo teórico e prático a respeito da diversidade cultural. O que acha dessas experiências para colocar em evidência as singularidades dos sujeitos?

Luiz Fernando Dias Duarte: Como já adiantei acima, esses movimentos diretamente comprometidos com terapêuticas culturalmente sensíveis são o que me parece dar continuidade às grandes contribuições da etnopsiquiatria original (Tobie Nathan não inventou a categoria, mas a reinvestiu) de Géza Roheim, de G. Devereux, de Weston La Barre, de Roger Bastide. São movimentos muito interessantes, com uma grande contribuição à acolhida de minorias culturais e grupos desfavorecidos em geral. Embora se considerem "psiquiátricos", vejo-os também como herdeiros das diferentes "antipsiquiatrias" dos anos 1960-70.

EntreRios - Revista do PPGANT -UFPI • ano 1, n. 2. 
EntreRios: $O$ ato odiento nas relações contemporâneas merece, no seu entender, um emprego interpretativo que circule suas manifestações como fenômenos sem precedentes, pelo menos se pensarmos dentro do perímetro da história da modernidade?

Luiz Fernando Dias Duarte: A antropologia cresceu vinculada ao preceito do trabalho localizado, focado em um contexto etnográfico preciso. Com isso, as manifestações sobre os grandes movimentos da história - que não faltaram - costumavam ser secundárias e não necessariamente bem articuladas com as etnografias. De um modo geral, os autores que questionaram mais diretamente as premissas cosmológicas da cultura ocidental como um todo (ao produzirem comparações com seus materiais de campo) acabaram por produzir esquemas interpretativos do destino de nossa cultura e de nossas sociedades. Lévi-Strauss expressou-se sobre isso no Tristes Trópicos e nas suas páginas sobre a cultura japonesa. L. Dumont foi mais explícito, retomando toda a cosmologia ocidental, em sua comparação com a cosmologia hindu, e produzindo um diagnóstico de fenômenos odientos como o nazismo e o racismo. Roy Wagner, Marilyn Strathern, Tim Ingold, Viveiros de Castro e muitos dos que com eles compartilham críticas severas às noções ocidentais de "natureza" também expressam valorações sobre os desafios e impasses de "nossa" cosmovisão. O mesmo faz, com outros tons, Bruno Latour. Essas contribuições dialogam com autores não necessária ou estritamente antropólogos, como Donna Haraway, Judith Butler, Giorgio Agamben, Edgard Morin, Fritjof Capra etc. O tema da destruição das condições de reprodução da espécie humana no planeta vem avultando - com toda razão e oportunidade. Mas não apenas: gênero, violência, autonomia, consciência, relacionalidade, impõem-se com igual intensidade.

\section{Antropologia, realidade nacional e contemporaneidade}

EntreRios: Há alguns anos, durante uma abertura do congresso da Associação Brasileira de Antropologia (ABA), um palestrante lembrava do crescente número de novos cursos de pós-graduação em antropologia no Brasil, ao passo que também dizia: "bem, nós fomos responsáveis por esse crescimento, agora temos que saber o que fazer com ele!". A Antropologia brasileira sabe o que fazer com aquilo que ela ajudou a expandir nos últimos anos?

Luiz Fernando Dias Duarte: O campo antropológico (melhor do que a Antropologia) brasileiro lutou por fazer crescer as oportunidades acadêmicas e profissionais dos seus participantes, como sói fazer qualquer campo científico. Na luta pelos recursos escassos do Estado brasileiro, sempre foi necessário "mostrar serviço", ou seja demonstrar a vitalidade do campo, com mais numerosos programas de pós-graduação, revistas, congressos etc. Isso ocorreu sobretudo no período de expansão das bases universitárias públicas do sistema de ensino nacional, e da expansão das bases internacionais de intercâmbio e fertilização cruzada. No quadro de um Estado com preocupações sociais progressistas, abriram-se também crescentes possibilidades de profissionalização de antropólogos fora dos muros universitários. Esse quadro favorável vem desmoronando já há alguns anos, no bojo das crises financeiras e políticas do Estado nacional, produzindo um crescente sentimento de descompasso entre as ambições materializadas em formatos institucionais ambiciosos e a fragilidade assustadora das condições atuais de formação (bolsas, apoio a políticas afirmativas) e de profissionalização (suspensão de concursos, cerceamento de movimentos civis e de organizações não governamentais). O que se vai fazer desse quadro inquietante dependerá da ação concertada de todos nós, de nossas associações e instituições, num contexto adverso e obscuro. 
EntreRios: Que entradas para temas e programas de pesquisa podem ser consideradas como urgentes, se pensarmos o ambiente de uma sensibilidade ideal da Antropologia Social para com o contexto nacional ao qual ela está ou deveria estar imediatamente integrada? Agir com compromisso com as "urgências" ou inovar em enquadramentos e tentar produzir um outro olhar perspectivo sobre a realidade?

Luiz Fernando Dias Duarte: Acho muito difícil estabelecer metas ou "palavras de ordem" a uma disciplina das Humanidades, em relação às circunstâncias sociopolíticas em que se desenvolve. Há ritmos diferentes na trajetória de uma vida política nacional, por exemplo, e na trajetória de uma linha de pesquisa ou de uma orientação teórica no interior de uma disciplina. Isso é particularmente vívido para as ciências humanas, que devem operar em ritmos e circunstâncias observacionais e analíticas completamente diferentes das ciências duras. Entre estas, os vínculos entre "ciência pura", "ciência aplicada", "tecnologia" e "inovação" são completamente diversos, podendo ser direcionados para os interesses do Estado ou do mercado com uma certa rapidez. Isso não quer dizer que não devamos estar com nossos instrumentos analíticos afiados para a compreensão dos contextos mais sensíveis, críticos ou urgentes em que estamos enredados. Os antropólogos brasileiros têm uma boa tradição de ativismo político, voltado para a proteção das condições de reprodução física ou moral dos mais variados segmentos da Nação ou direitos ameaçados. O que os habilita a se tornarem intelectuais respeitáveis nos debates políticos não é, porém, a sua militância em si, mas o reconhecimento público de sua contribuição ao conhecimento - muitas vezes autônoma em relação às condições externas de seu trabalho. 